\title{
LA PRIVACIÓN DEL EJERCICIO DE DERECHO DE SUFRAGIO ACTIVO DE LAS PERSONAS CON \\ LA CAPACIDAD MODIFICADA JUDICIALMENTE. COMENTARIO AL AUTO DEL TRIBUNAL CONSTITUCIONAL 196/2016, DE 28 DE NOVIEMBRE
}

The deprivation of the right to vote to individuals with judicially modified capacity. Analysis of the Constitutional Court Resolution 196/2016, of 28th of November

\author{
JUAN GÓMEZ-RIESCO TABERNERO DE PAZ \\ Universidad de Salamanca \\ igomez-riesco@notariado.org
}

Cómo citar/Citation

Gómez-Riesco Tabernero de Paz, J. (2017).

La privación del ejercicio de derecho de sufragio activo de las personas con la capacidad modificada judicialmente. Comentario al Auto del Tribunal Constitucional 196/2016, de 28 de noviembre.

Derecho Privado y Constitución, 31, 243-274.

doi: https://doi.org/10.18042/cepc/dpc.31.06

(Recepción:19/08/2017. Aceptación tras revisión: 18/09/2017. Publicación: 27/11/2017)

\section{Resumen}

El art. 3.1.b) de la Ley Orgánica 5/1985, de 19 de junio, del Régimen Electoral General admite la posibilidad de que las personas incapacitadas judicialmente puedan ser privadas del derecho de sufragio activo en virtud de una sentencia firme de incapacitación que así lo determine expresamente, discutiéndose, en este trabajo, comentario al Auto del Tribunal Constitucional 196/2016, si ello es conforme a los arts. 23.1 
y 14 de la Constitución española, así como a la Convención de las Naciones Unidas sobre los Derechos de las Personas con Discapacidad, firmada en Nueva York el 13 de diciembre de 2006, que ha de aplicarse en la interpretación de las normas relativas a los derechos fundamentales, como es el caso del art. 3 de la Ley Orgánica de Régimen Electoral General, por exigencia del art. 10.2 de la Constitución española, tanto en sí mismo considerado, como en la aplicación que se haga de dicho precepto por los tribunales ordinarios en consideración a la situación concreta en que se encuentre la persona discapacitada cuya capacidad quede judicialmente modificada en atención a las circunstancias concurrentes en aquella y en su entorno.

\title{
Palabras clave
}

Derecho de sufragio activo; discapacidad; incapacidad; capacidad judicialmente modificada.

\begin{abstract}
This paper analyses, while commenting Resolution 196/2016 of the Constitutional Court, whether the deprivation of the right to vote of a citizen decided by a Tribunal on grounds of the incapacity judicially declared of that individual, envisaged by article 3.1.b) of Organic Act 5/1985, of $19^{\text {th }}$ of June, on the General Electoral Regime, is compatible, in its wording and its application -with regard to the specific situation and background in which a disabled person may be found-, with articles 23.1 and 14 of the Spanish Constitution and the United Nations Convention on the Rights of Persons with Disabilities, signed in New York on the 13th of December 2006, that has to be applied in the interpretation of norms related to fundamental rights - which is the case of article 3 LOREG-, in accordance with article 10.2 of the Constitution.
\end{abstract}

\section{Keywords}

Right to vote; disability; incapacity; judicially modified capacity. 


\section{SUMARIO}

I. ANTECEDENTES Y SUPUESTO DE HECHO. II. COMENTARIO AL AUTO DEL TRIBUNAL CONSTITUCIONAL 196/2016, DE 28 DE NOVIEMBRE: 1. ¿̇abe la privación del ejercicio derecho de sufragio activo de los declarados incapaces o personas con capacidad modificada judicialmente? Interés particular de la persona privada del ejercicio del derecho de sufragio vs. interés general por un correcto funcionamiento del sistema electoral. 2. ¿̇s discriminatoria la privación del ejercicio del derecho de sufragio de la persona declarada incapaz o cuya capacidad haya sido modificada judicialmente?: distinción entre discapacidad, incapacidad e incapacitación o capacidad modificada judicialmente. 3. Garantías en el proceso concreto de declaración de incapacitación o modificación judicial de la capacidad con privación del ejercicio del derecho de sufragio activo. III. CONCLUSIONES. BibLIOGRAFía.

\section{ANTECEDENTES Y SUPUESTO DE HECHO}

En el Auto 196/2016, de 28 de noviembre, el Tribunal Constitucional (TC) desestima el recurso de súplica del Ministerio Fiscal sobre la inadmisión del recurso de amparo 2415-2016 contra la Sentencia de 17 de marzo de 2016, dictada por la Sala de lo Civil del Tribunal Supremo (TS), desestimatoria del Recurso de Casación 1624-2015 formulado frente a la Sentencia de la Sección Sexta de la Audiencia Provincial de A Coruña, de 11 de marzo de 2015, recaída en autos de juicio verbal núm. 1582-2015 del Juzgado de Primera Instancia núm. 6 de Santiago de Compostela.

En este Juzgado de Primera Instancia, ante una demanda de los interesados, se declaró la incapacitación parcial de la demandada para gobernarse por sí misma y para administrar sus bienes, se rehabilitó la patria potestad de sus padres y se privó del ejercicio por aquella del derecho de sufragio activo no obstante la solicitud de los padres demandantes de que pudiera seguir disfrutando de este derecho. 
La apelación de dicha sentencia, así como el recurso de casación planteado por los mismos demandantes contra la decisión de la privación del ejercicio de derecho de sufragio activo de la demandada, dieron como resultado la ratificación de lo estimado por el Tribunal de Primera Instancia, frente a lo cual se presentó el recurso de amparo ante el TC por vulneración del art. 23.1 de la Constitución española (CE) en relación con la interpretación que debe darse a las normas relativas a los derechos fundamentales y las libertades al amparo del art. 10.2 CE, de acuerdo con lo dispuesto en los arts. 29, 5 y 2 de la Convención de las Naciones Unidas sobre los Derechos de las Personas con Discapacidad, firmada en Nueva York el 13 de diciembre de 2006 (en adelante, la Convención de Nueva York), así como por la vulneración del mismo art. 23.1 CE en relación con el derecho de igualdad de los ciudadanos ante la ley previsto en el art. $14 \mathrm{CE}$, a la luz del criterio interpretativo establecido en la Convención de Nueva York.

Inadmitido dicho recurso de amparo, el Ministerio Fiscal planteó el correspondiente recurso de súplica contra dicha inadmisión a trámite, también desestimado mediante el auto objeto del presente comentario, en el que se motiva dicha inadmisión.

\section{COMENTARIO AL AUTO DEL TRIBUNAL CONSTITUCIONAL 196/2016, DE 28 DE NOVIEMBRE}

En el auto del TC desestimatorio del recurso de súplica del Ministerio Fiscal por la inadmisión del recurso de amparo referido, se suscitan diversas cuestiones de importancia ${ }^{1}$.

1 La magistrada Asua Batarrita, en su voto discrepante, se refiere a la oportunidad desaprovechada, por no haberse admitido a trámite el recurso de amparo planteado por la parte demandante, para haberse pronunciado el TC «estableciendo una precisa doctrina, en interpretación del derecho fundamental consagrado en el art. 23.1 CE, en cuanto a su ejercicio por las personas afectadas de una discapacidad, teniendo en cuenta los criterios hermenéuticos que ofrece el art. 10.2 CE, así como los mandatos contenidos en los arts. 9.2 y $49 \mathrm{CE}$ », «ya que no existe doctrina de este Tribunal en relación con el ejercicio del derecho fundamental al voto, reconocido en el art. 23.1 CE, cuando se trata de personas con discapacidad intelectual», a lo cual se une, según continúa la magistrada, «la trascendencia del asunto [...] por afectar a un importante colectivo en situación de especial vulnerabilidad por razón de su discapacidad». 


\section{1. ¿CABE LA PRIVACIÓN DEL EJERCICIO DERECHO DE SUFRAGIO ACTIVO DE LOS DECLARADOS INCAPACES O PERSONAS CON CAPACIDAD MODIFICADA JUDICIALMENTE'? ? INTERÉS PARTICULAR DE LA PERSONA PRIVADA DEL EJERCICIO DEL DERECHO DE SUFRAGIO VS. INTERÉS GENERAL POR UN CORRECTO FUNCIONAMIENTO DEL SISTEMA ELECTORAL}

Conforme al art. 3.1 letra b) de la Ley Orgánica 5/1985, de 19 de junio, del Régimen Electoral General (LOREG), "carecen de derecho de sufragio [...] b) Los declarados incapaces en virtud de sentencia judicial firme, siempre que la misma declare expresamente la incapacidad para el ejercicio del derecho de sufragio». El apdo. 2 del mismo art. 3 añade que «a los efectos previstos en este artículo, los Jueces o Tribunales que entiendan de los procedimientos de incapacitación o internamiento deberán pronunciarse expresamente sobre la incapacidad para el ejercicio de sufragio. En el supuesto en que esta sea apreciada, lo comunicarán al Registro Civil para que se proceda a la anotación correspondiente» ${ }^{3}$.

Resulta, de acuerdo con este precepto legal, que, en estas situaciones y con la correspondiente sentencia judicial firme de incapacitación que expresamente establezca dicha previsión, la persona incapacitada puede quedar privada del ejercicio del derecho de sufragio activo.

Se discute, sin embargo, por la parte recurrente en amparo, si esta posibilidad de privación del ejercicio del derecho de sufragio activo, que regula el art. 3.1 LOREG en su párrafo b), es conforme a la CE desde una doble

2 Nueva denominación empleada en sustitución de los términos de incapaz o incapacitación, introducida por la Ley 15/2015, de 2 de julio, de la Jurisdicción Voluntaria, como señala su preámbulo, al final de su apdo. III, con la finalidad de adaptar la legislación española a la Convención de Nueva York, firmada en Nueva York el 13 de diciembre de 2006 y ratificada por España mediante Instrumento de 23 de noviembre de 2007, y en vigor de forma general y para España el 3 de mayo de 2008. No obstante, el uso de esta nueva terminología en nuestro ordenamiento jurídico todavía no es completa, pues existen numerosos cuerpos legales como el Código Civil, la Ley de Enjuiciamiento Civil o la LOREG, cuyo art. 3 es objeto de análisis en el presente comentario, que siguen haciendo referencia a la denominación anterior de incapaz o incapacitación, y que por ello también se siguen empleando en este trabajo.

3 La Junta Electoral Central ha señalado la imposibilidad de impedir el ejercicio del derecho de sufragio de los disminuidos psíquicos si no se encuentran legalmente incapacitados y privados por la propia sentencia de incapacitación del derecho de sufragio (Acuerdos de 5 de mayo de 1977, 21 de abril de 1983, 27 de febrero de 1990, 5 de junio de 1991 y 3 de junio de 2003). Véase Gálvez Muñoz y Rubio Lara (2007: 104). 
perspectiva: 1) por un lado, en relación con el art. 23.1 CE, que consagra el derecho fundamental al sufragio activo ${ }^{4}$, bien en sí mismo considerado, bien combinado con el art. 10.2 CE, según el cual, las normas relativas a los derechos fundamentales deben interpretarse a la luz de los tratados internacionales de los que España sea parte, y, en este caso, particularmente, a la luz de lo dispuesto en el art. 29 de la Convención de Nueva York'; y, 2) por otro lado,

4 Dispone el art. 23.1 CE que «Los ciudadanos tienen el derecho a participar en los asuntos públicos, directamente o por medio de sus representantes, libremente elegidos en elecciones periódicas por sufragio universal».

5 El art. 29 de la Convención de Nueva York dispone que «Los Estados Partes garantizarán a las personas con discapacidad los derechos políticos y la posibilidad de gozar de ellos en igualdad de condiciones con las demás y se comprometerán a: a) Asegurar que las personas con discapacidad puedan participar plena y efectivamente en la vida política y pública en igualdad de condiciones con las demás, directamente o a través de representantes libremente elegidos, incluidos el derecho y la posibilidad de las personas con discapacidad a votar y ser elegidas, entre otras formas mediante:

i) La garantía de que los procedimientos, instalaciones y materiales electorales sean adecuados, accesibles y fáciles de entender y utilizar;

ii) La protección del derecho de las personas con discapacidad a emitir su voto en secreto en elecciones y referéndum públicos sin intimidación, y a presentarse efectivamente como candidatas en las elecciones, ejercer cargos y desempeñar cualquier función pública a todos los niveles de gobierno, facilitando el uso de nuevas tecnologías de apoyo cuando proceda;

iii) La garantía de la libre expresión de la voluntad de las personas con discapacidad como electores y a este fin, cuando sea necesario y a petición de ellas, permitir que una persona de su elección les preste asistencia para votar;

b) Promover activamente un entorno en el que las personas con discapacidad puedan participar plena y efectivamente en la dirección de los asuntos públicos, sin discriminación y en igualdad de condiciones con las demás, y fomentar su participación en los asuntos públicos y, entre otras cosas:

i) Su participación en organizaciones y asociaciones no gubernamentales relacionadas con la vida pública y política del país, incluidas las actividades y la administración de los partidos políticos;

ii) La constitución de organizaciones de personas con discapacidad que representen a estas personas a nivel internacional, nacional, regional y local, y su incorporación a dichas organizaciones».

En este mismo sentido, el art. 53 del Texto Refundido de la Ley General de Derechos de las Personas con Discapacidad y de su Inclusión Social, aprobado por Real Decreto Legislativo 1/2013, de 29 de noviembre, establece que: «Las personas con discapacidad podrán ejercer el derecho a la participación en la vida política y en los procesos electorales en igualdad de condiciones que el resto de los ciudadanos conforme a la 
en relación con el art. $14 \mathrm{CE}$, que establece la igualdad de todos los españoles ante la ley, sin que pueda prevalecer discriminación alguna por cualquier condición y circunstancia personal o social, y, particularmente, en este caso, por razón de la discapacidad de la demandada, incapacitada parcialmente y privada del ejercicio del derecho de sufragio activo, objeto de este análisis.

Asimismo, el Ministerio Fiscal, en su recurso de súplica, en línea con lo argumentado por la parte demandante y recurrente en amparo, contempla la posible lesión constitucional de los derechos fundamentales de igualdad ante la ley y el derecho de sufragio activo previstos en los arts. 14 y $23 \mathrm{CE}$ citados en la "propia previsión legal del art. 3 LOREG o bien en la interpretación y aplicación jurisprudencial que se está haciendo de esta disposición legal», aunque sin perjuicio de la referencia a que se hará mención, más adelante, relativa a la aplicación en concreto del art. 3 LOREG, no se recoge en el auto argumento alguno del Ministerio Fiscal en contra de la constitucionalidad de la "propia previsión legal del art. 3 LOREG», por lo que parece criticable que el Ministerio Fiscal plantee tal cuestión, aunque de manera tangencial, sin argumentar el motivo por el que la previsión legal, en sí misma, pueda considerarse inconstitucional.

En cuanto a la primera duda de inconstitucionalidad por vulneración del art. 23.1 CE propiamente dicho, la parte recurrente en amparo, sin perjuicio de lo mencionado por el Ministerio Fiscal en relación con su posible vulneración en la aplicación concreta de la norma, aduce, según nos dice el auto, que el art. 23.1 CE «no contempla excepción» al derecho a participar en asuntos públicos por medio del voto "y que este derecho no está ligado a la posesión de un determinado nivel de conocimientos, o competencias, o de renta, ni a la acreditación de buena conducta, sino a la condición de ciudadano, circunstancia que convierte al sufragio en universal» (art. $68 \mathrm{CE}$ ). Este derecho de sufragio activo se reconoce a todos los ciudadanos sin limitaciones, según la parte recurrente, por lo que las privaciones a su ejercicio previstas por el art. 3, apdos. 1 b) y 2 LOREG serían contrarias a la CE.

Por otra parte, alega la parte recurrente que el citado art. 3.1.b) LOREG debe interpretarse conforme al art. 29 de la Convención Internacional sobre los derechos de las Personas con Discapacidad (ex art. 10.2 CE), que no se encontraba vigente al aprobarse la LOREG, que en su apdo. a) indica que los Estados miembros se comprometen «a asegurar que las personas con discapacidad puedan participar plena y efectivamente en la vida política y pública en igualdad de condiciones con los demás, directamente o a través de represen-

normativa en vigor. Para ello las administraciones públicas pondrán a su disposición los medios y recursos que precisen». 
tantes libremente elegidos, incluidos el derecho y la posibilidad de las personas con discapacidad a votar y ser elegidas», por lo que el art. 3.1.b) LOREG no debería haberse aplicado por el tribunal, por oponerse al art. 29 referido, de aplicación preferente.

La parte demandante contempla, de este modo, el derecho fundamental de sufragio activo como un derecho no susceptible de privación ni restricción alguna, por entender que corresponde a todo ciudadano por el mero hecho de serlo, tanto al amparo del art. 23.1 CE como de lo estipulado por el art. 29 de la Convención de Nueva York, por lo que parece que estima que es un derecho sin límite alguno en cuanto a su titularidad y sin posible restricción en su ejercicio, desconociendo, sin embargo, el hecho de que ningún derecho fundamental puede ser considerado como absoluto, como ha señalado la doctrina del TC en múltiples ocasiones.

La magistrada discrepante afirma que el art. 3 LOREG, a los efectos del art. 23.1 CE, interpretado en consonancia con el art. 29 de la Convención de Nueva York, es un precepto insuficiente, carente de los elementos esenciales, dirigido a privar del derecho y sin mención alguna que oriente a facilitar su ejercicio, y que, aun prescindiendo de la Convención de Nueva York, se separa de las exigencias constitucionales si se cohonesta con los arts. 9.2 y $49 \mathrm{CE}$. Ni el art. 23.1 CE recoge las razones por las que una persona discapacitada podría ser privada de su derecho de voto, ni esas razones se explicitan tampoco en el art. 3.1.b) LOREG, que no establece ningún criterio ni estándares mínimos a los cuales deban sujetarse los órganos judiciales, de manera que la privación del derecho de voto de los discapacitados queda absolutamente remitida al libre criterio judicial en un procedimiento que debería encontrarse presidido por el beneficio del incapacitado y que debería tender, conforme al art. 29 de la Convención de Nueva York, a remover los obstáculos y facilitar los medios necesarios para que las personas con discapacidad, independientemente de su deficiencia, tuvieran derecho a votar y a participar en la vida pública de la misma forma que los demás ciudadanos.

La magistrada discrepante señala, asimismo, que la Sentencia del TC (STC) 153/2014, de 25 de septiembre, pone de relieve que la atribución por parte de la CE de los derechos de participación política a los ciudadanos españoles en los arts. 13.2 y $23.1 \mathrm{CE}$ - con las excepciones a favor de los extranjero que se disponen en el propio art. 13.2 CE- admite modulaciones en su ejercicio siempre que vengan establecidas en preceptos de la propia norma fundamental, lo que no sucede en el presente caso.

El TC, sin embargo, en este supuesto, en particular, del derecho de sufragio, al rechazar el recurso de súplica del Ministerio Fiscal, en su Fundamento Jurídico (FJ) 2, nos recuerda que este es un derecho fundamental de configu- 
ración legal ${ }^{6}$ como ha señalado la misma STC 153/2014, de 25 de septiembre, en su FJ 3, según la cual, "la participación ha de sustanciarse en los términos en que el precepto haya sido desarrollado por el legislador electoral (arts. 53.1 y 81.1 CE), siempre que dicho desarrollo no menoscabe el contenido esencial del derecho fundamental ni infrinja los preceptos constitucionales». Y añade el FJ 7 de la referida STC que «la determinación de las condiciones que afectan a la titularidad y ejercicio del derecho de sufragio se sitúan en el dominio del legislador electoral». Y siendo, por tanto, un derecho fundamental de configuración legal, y habiéndose contemplado estas posibles causas de privación en su ejercicio, el TC considera que no es un derecho per se incompatible con la posibilidad de privación singularizada, por causa legalmente prevista, sobre todo cuando dicha privación está revestida de la garantía judicial.

Critica la magistrada discrepante este argumento de que el derecho consagrado en el art. 23.1 CE es un derecho fundamental de configuración legal, pues ello permitiría afirmar que los apdos. 1.b) y 2 del art. 3 LOREG «son constitucionales por su propia regulación, a la que la Constitución se remite poco menos que en blanco, lo que nos lleva al inadmisible corolario de que ninguna de las leyes que desarrolle derechos fundamentales podría ser inconstitucional en la medida en que se trate de derechos de configuración legal, como si el contenido de tales derechos quedara establecido íntegramente en cada caso por el legislador orgánico». Sin embargo, añade la magistrada, «ese argumento incurre en un olvido imperdonable: el legislador debe respetar en todo caso el contenido esencial del derecho derivado de la Constitución", en lo cual la magistrada incurre en un error, pues, como se ha señalado previamente, el propio TC hace referencia al respeto a ese contenido esencial, aunque no lo defina.

De este modo, los contornos y el modo de ejercicio del derecho vendrán definidos por el legislador, si bien, claro está, cuál sea el contenido esencial de este derecho y el respeto a este es lo que habrá que tener en cuenta para determinar si las restricciones o el modo en que se configure legalmente atenta o no contra el mismo derecho y, por tanto, si dicha configuración legal es o no contraria a la $\mathrm{CE}$. Concretamente, en el caso de las personas privadas del ejercicio del derecho de sufragio activo por haberse establecido de este modo mediante sentencia judicial en que se declare expresamente en virtud de un procedimiento de incapacitación o modificación judicial de la capacidad, hay que valorar si la causa de privación del derecho es contraria a este contenido

6 Véanse artículos 68.1 CE respecto del Congreso, 69.1 CE respecto del Senado, 140 en relación con los ayuntamientos y 152 en lo concerniente a las asambleas legislativas de las comunidades autónomas. 
esencial del derecho de sufragio activo, o si está basada en razones lógicas que justifican esta privación. Esta es la cuestión que es preciso dilucidar, tanto en cuanto a la incapacidad como causa de privación del ejercicio del derecho de sufragio como al modo y procedimiento en el que se acuerde su aplicación a una persona en concreto.

En el ámbito de este derecho fundamental de sufragio activo, se argumenta por los demandantes de amparo, en este caso, asimismo, únicamente desde la perspectiva de la persona declarada incapaz, que desea votar y que ya ha votado en alguna oportunidad, y se estima que el ejercicio del derecho de sufragio no le ocasiona ningún perjuicio que fundamente su privación por razón del daño que pueda sufrir la persona declarada incapaz al ejercitar su derecho al voto. Se podría considerar, en sentido contrario, que esta argumentación implica una apreciación del derecho de sufragio reducida, ya que, por un lado, este derecho no debe analizarse, exclusivamente, desde el punto de vista del ciudadano como titular del derecho de sufragio a quien corresponde su ejercicio, sino desde una perspectiva más amplia, ya que este derecho se incardina en el marco del sistema electoral en su conjunto y en la finalidad que este pretende; esto es, obtener un resultado acorde con el adecuado ejercicio del derecho de voto, de modo personal, libre y secreto, emitido para la configuración de los correspondientes órganos representativos que articulan nuestro sistema político e institucional y que, por tanto, no solo responde a un interés particular del votante o ciudadano en concreto, sino a un interés general de que el sistema electoral funcione correctamente y no se vea sometido a resultados que puedan obtenerse mediante votos emitidos que vulneren los principios de personalidad, libertad y secreto del voto bajo coacción o manipulación, lo que pondría en riesgo la pureza de las elecciones.

Parece lógico que, si una persona se halla en una situación de falta de desarrollo cognitivo o de discernimiento por alguna razón que le impida proceder al ejercicio del derecho de voto en condiciones iguales al resto de los ciudadanos, esto es, de modo personal, libre y secreto, una vez acreditado dicho extremo en un procedimiento judicial de incapacitación, analizadas las circunstancias concretas, pueda ser privada del ejercicio del derecho de sufragio, con las debidas garantías, no solo para su mayor protección por carecer de la capacidad natural necesaria para ejercitar este derecho con pleno conocimiento de causa y en libertad, sino también por un interés general de la sociedad de que no se produzca el voto por esa persona que no tiene el entendimiento suficiente y evitar, así, que tenga lugar una distorsión del correcto funcionamiento y desarrollo de los procesos electorales, y, en tal sentido, considerar posible, válida y constitucional la privación del derecho de sufragio contemplada en el art. 3.1.b) LOREG objeto de este análisis. 
Del propio art. 29 de la Convención de Nueva York, citado como apoyo para entender el carácter del derecho de sufragio como absoluto y no susceptible de privación, se deduce la posibilidad de que este pueda verse limitado cuando en el inciso ii) de la letra a) se indica que los Estados miembros deberán asegurar «la protección del derecho de las personas con discapacidad a emitir su voto en secreto en elecciones y referéndum públicos sin intimidación», y en el inciso iii) de la misma letra a) de este art. se refiere a «la garantía de la libre expresión de la voluntad de las personas con discapacidad como electores y a este fin, cuando sea necesario y a petición de ellas, permitir que una persona de su elección les preste asistencia para votar». Luego, este art. 29 de la Convención de Nueva York hace referencia al secreto del voto ejercido sin intimidación, así como a la libertad de expresión de la voluntad electoral y la posibilidad de designar a una persona que los asista en su ejercicio. De ello puede colegirse que el secreto y la libertad del voto, como rasgos esenciales del ejercicio del derecho de sufragio, han de quedar garantizados y, por tanto, cabe entender que, en caso de que no sea posible ejercitar el derecho de sufragio con estas garantías y conforme a tales principios, por la situación en que se encuentre la persona con discapacidad, pueda tener lugar esa limitación o privación de ejercicio del derecho de sufragio mencionada, y, más concretamente, en el caso en que no pueda expresar libremente su voluntad como elector.

El argumento de que el ejercicio del derecho de sufragio activo no produce perjuicio alguno a la persona declarada incapaz a la que se priva de dicho ejercicio y que, por tanto, debería permitírsele votar no deja de ser peligroso porque, además de poder implicar un posible perjuicio al interés general y al funcionamiento eficaz del sistema electoral, antes mencionado, podría entenderse como una banalización del ejercicio de tal derecho, que, como señala la jurisprudencia a que se remite el auto, no es un derecho que se limite al mero hecho de depositar una papeleta en una urna. Considerar que el ejercicio de este derecho de voto no perjudica en nada al declarado incapaz coloca el derecho de sufragio activo en un plano inferior a otros derechos que la persona cuya capacidad se modifique judicialmente no puede ejercitar debido a su situación particular. Pensar que una persona incapacitada puede votar porque el ejercicio de este derecho no le supone, en ningún caso, un daño directo y que no le acarrea consecuencia negativa alguna, sería devaluar y desconocer la importancia del derecho de sufragio activo y su correcto ejercicio, ya que si una persona no puede tomar una decisión de voto en determinado sentido por carecer de la capacidad natural suficiente para ello, no podrá ejercitar su derecho de voto de modo personal, libre y secreto, y, en caso de votar lo estaría haciendo de modo inducido o decidido por otra persona, lo cual sería contrario al sentido y finalidad del art. 23.1 CE y al contenido propio del derecho de sufragio activo. 


\section{2. ¿̇ES DISCRIMINATORIA LA PRIVACIÓN DEL EJERCICIO DEL DERECHO DE SUFRAGIO DE LA PERSONA DECLARADA INCAPAZ O CUYA CAPACIDAD HAYA SIDO MODIFICADA JUDICIALMENTE?: DISTINCIÓN ENTRE DISCAPACIDAD, INCAPACIDAD E INCAPACITACIÓN O CAPACIDAD MODIFICADA JUDICIALMENTE}

Como se ha señalado previamente, se discute también la constitucionalidad de la privación del ejercicio del derecho de sufragio de la persona incapacitada judicialmente por vulneración del principio de igualdad consagrado en el art. $14 \mathrm{CE}$ y en el art. 12.2 de la Convención de Nueva York, que, como recuerda la parte recurrente en amparo, obliga a los Estados miembros a reconocer capacidad jurídica de las personas con discapacidad «en igualdad de condiciones con las demás en todos los aspectos de la vida», no siendo razonable la diferencia de trato cuando la prohibición se impone al promover un procedimiento de incapacidad cuya finalidad es el «beneficio del tutelado», sin que se haya probado que le ocasiona un perjuicio el ejercicio del derecho de sufragio, por lo que el trato desigual frente a los demás ciudadanos a quienes no se les somete a un test de conocimientos políticos y electorales, ni se examina su grado de influenciabilidad, carece de justificación objetiva y razonable». Y abunda en que la discapacidad no es un motivo que pueda servir para sustentar discriminación alguna, como ha indicado la STC 269/1994, de 3 de octubre, lo que resultaría, asimismo, de la interpretación del art. 14 CE conforme al art. 21.1 de la Carta de Derechos Fundamentales de la Unión Europea $(\mathrm{CDFUE})^{7}$, que se refiere expresamente a esta circunstancia, y al propio art. 5 de la Convención de Nueva York ${ }^{8}$, que prohíbe expresamente la discriminación por motivo de discapacidad.

Respecto de la argumentación referente a la vulneración del principio de igualdad del art. 14 CE por discriminación de las personas con discapa-

$7 \quad$ El art. 21.1 CDFUE establece que «Se prohíbe toda discriminación, y en particular la ejercida por razón de sexo, raza, color, orígenes étnicos o sociales, características genéticas, lengua, religión o convicciones, opiniones políticas o de cualquier otro tipo, pertenencia a una minoría nacional, patrimonio, nacimiento, discapacidad, edad u orientación sexual».

$8 \quad$ El art. 5 de la Convención de Nueva York dispone lo siguiente:

«1. Los Estados miembros reconocen que todas las personas son iguales ante la ley y en virtud de ella y que tienen derecho a igual protección legal y a beneficiarse de la ley en igual medida sin discriminación alguna.

2. Los Estados miembros prohibirán toda discriminación por motivos de discapacidad y garantizarán a todas las personas con discapacidad protección legal igual y efectiva contra la discriminación por cualquier motivo. 
cidad como causa de privación del ejercicio del derecho de sufragio, el TC, muy acertadamente a mi entender, señala, en su FJ 3, que «debe tenerse en cuenta, en primer término, la distinción entre «discapacidad» en el sentido de la Convención, concepto muy amplio en que tiene cabida cualquier deficiencia física, mental, intelectual o sensorial a largo plazo» que pueda impedir la efectiva igualdad (art. 1 de la Convención de Nueva York), de «incapacidad» en el sentido definido por el Código Civil (CC) «enfermedades o deficiencias persistentes de carácter físico o psíquico que impidan a la persona gobernarse por sí misma [art. $200 \mathrm{CC}$ ] y concretado respecto del ejercicio del derecho que nos ocupa en el art. 3 LOREG».

Continúa el TC, en el mismo FJ del auto, señalando que en el art. 3 LOREG «se trata de la capacidad de la persona [de cada persona] para emitir el voto como «libre expresión de la voluntad del elector», lo que también garantiza la Convención de Nueva York [art. 29 a) iii)], cuya finalidad se inscribe, más bien, en la línea con el mandato contenido en el art. 9.2 CE, de remover los obstáculos que impidan o dificulten la emisión del voto libre, secreto y sin intimidación [apdo. a) II y III del art. 29] de las personas con discapacidad, llegando a garantizar que «cuando sea necesario y a petición de ellas» que «una persona de su elección les preste asistencia para votar».

«Partiendo de este ámbito de aplicación y finalidad diferentes», el TC entiende que las razones de los recurrentes «no siembran duda sobre la compatibilidad del art. 29» de la Convención de Nueva York «y el art. 3.1.b)

3. A fin de promover la igualdad y eliminar la discriminación, los Estados miembros adoptarán todas las medidas pertinentes para asegurar la realización de ajustes razonables.

4. No se considerarán discriminatorias, en virtud de la presente Convención, las medidas específicas que sean necesarias para acelerar o lograr la igualdad de hecho de las personas con discapacidad».

Entre las definiciones del art. 2 de la Convención de Nueva York se señala que: «Por «discriminación por motivos de discapacidad» se entenderá cualquier distinción, exclusión o restricción por motivos de discapacidad que tenga el propósito o el efecto de obstaculizar o dejar sin efecto el reconocimiento, goce o ejercicio, en igualdad de condiciones, de todos los derechos humanos y libertades fundamentales en los ámbitos político, económico, social, cultural, civil o de otro tipo. Incluye todas las formas de discriminación, entre ellas, la denegación de ajustes razonables». Y por «ajustes razonables» se entenderán «las modificaciones y adaptaciones necesarias y adecuadas que no impongan una carga desproporcionada o indebida, cuando se requieran en un caso particular, para garantizar a las personas con discapacidad el goce o el ejercicio, en igualdad de condiciones con las demás, de todos los derechos humanos y libertades fundamentales.» 
LOREG, tal y como han sido conciliados en la más reciente jurisprudencia del Tribunal Supremo».

Abunda, asimismo, el razonamiento del TC, en el sentido de señalar que tampoco queda suficientemente argumentada la posible discriminación por razón de discapacidad por el art. 3 LOREG, que sería contraria al art. 14 $\mathrm{CE}$, por cuanto «el precepto en cuestión no priva del derecho de voto a los «discapacitados» como grupo o colectivo, y por razón de cualquier discapacidad», sino que «atribuye a los órganos judiciales la función de decidir sobre tal restricción del ejercicio del derecho fundamental de modo individualizado, en razón a las concretas circunstancias de cada persona y tras el oportuno proceso». La privación de este derecho no se aplica a las personas por el hecho de padecer cualquier discapacidad, sino solo a aquellas respecto de las que así se decida por sentencia, tras el oportuno proceso, con las debidas garantías de defensa y prueba, y «en razón de la concreta disfuncionalidad que padecen y que se proyecte sobre su capacidad intelectiva y volitiva respecto del ejercicio del derecho de voto». La restricción únicamente debe afectar, continúa diciendo el TC, «a las personas que carecen del mínimo entendimiento y voluntad precisos para ejercer el voto libre que proclama el artículo 23.1 CE.»

La finalidad de las medidas previstas por el art. 29 de la Convención de Nueva York es garantizar el efectivo ejercicio del derecho de voto, un fiel reflejo de la libre voluntad de la persona con discapacidad y «no la mera introducción de la papeleta electoral en una urna».

Efectivamente, la distinción entre discapacidad e incapacidad que establece el TC en su FJ 3 es esencial para abordar esta posibilidad de privación del ejercicio del derecho de sufragio y su constitucionalidad, en la forma en que esta se regula actualmente en la LOREG, así como el que sea conforme con la Convención de Nueva York, tantas veces citada.

La discapacidad, como afirma el TC, tal y como se aborda en la Convención de Nueva York, que no la define, es un concepto muy amplio en el que tiene cabida cualquier tipo de deficiencia física, mental, intelectual o sensorial a largo plazo que, al interactuar con diversas barreras, pueda impedir la efectiva igualdad, y trata de evitar que estas circunstancias den lugar a un trato discriminatorio'; mientras que el concepto de incapacidad, mucho más

9 El art. 1, en su párrafo segundo, de la Convención de Nueva York, establece que «Las personas con discapacidad incluyen a aquellas que tengan deficiencias físicas, mentales, intelectuales o sensoriales a largo plazo que, al interactuar con diversas barreras, puedan impedir su participación plena y efectiva en la sociedad, en igualdad de condiciones con las demás». No obstante, no recoge una definición propiamente dicha de 
restringido, se menciona en el art. 200 de nuestro CC en cuanto a la imposibilidad para una persona de gobernarse por sí misma.

La magistrada Asua Batarrita, en su voto discrepante, pone de manifiesto, por una parte, la existencia, a su entender, de una clara incompatibilidad entre los apartados 1.b) y 2 del art. 3 LOREG y el art. 29.a) de la Convención de Nueva York:

[...] pues mientras el artículo 3 LOREG se fundamenta en la «discapacidad» ${ }^{10}$ como impedimento para ostentar el derecho de sufragio, el art. 29 de la Convención de Nueva York descansa en la filosofía opuesta, esto es, la de ofrecer todos los medios precisos para que los discapacitados puedan participar en la vida pública en pie de igualdad con los demás ciudadanos.

Asimismo, por otra parte, tacha esta distinción que señala el TC entre discapacidad e incapacidad, de "fútil argumento», y considera que ni el CC es canon interpretativo de los preceptos constitucionales ni su art. 200 regula la «incapacidad», sino la «incapacitación» de la persona; una incapacitación que solo puede acordarse por sentencia judicial en virtud de las causas establecidas en la ley mediante un procedimiento en el que se respeten de forma escrupulosa los trámites o diligencias exigidas legalmente (así, por todas, STC 7/2011, de 14 de febrero, FJ 2). Y que el auto en cuestión está distorsionando los planos en su intento de introducir una distinción improcedente; y que incapacitación y discapacidad no son conceptos incompatibles, pues aquella recae, en todo caso, sobre personas que se encuentran, efectivamente, afectadas de una discapacidad física o psíquica.

Si bien es cierto, como puntualiza la magistrada discrepante, que todas las personas incapaces en el sentido del art. 200 CC adolecen de alguna dis-

la discapacidad, como tal, en el art. 2, dedicado a las «Definiciones» en relación con la Convención de Nueva York.

El art. 2 del Texto Refundido de la Ley General de Derechos de las Personas con Discapacidad y de su Inclusión Social, aprobado por Real Decreto Legislativo 1/2013, de 29 de noviembre, define la discapacidad como una «situación que resulta de la interacción entre las personas con deficiencias previsiblemente permanentes y cualquier tipo de barreras que limiten o impidan su participación plena y efectiva en la sociedad, en igualdad de condiciones con las demás»; y, en su art. 4.1 dispone que «Son personas con discapacidad aquellas personas que presentan deficiencias físicas, mentales, intelectuales o sensoriales, previsiblemente permanentes que, al interactuar con diversas barreras, puedan impedir su participación plena y efectiva en la sociedad, en igualdad de condiciones con los demás".

10 El art. 3 LOREG no emplea el término de discapacidad, sino el de «incapacidad». 
capacidad, sin embargo, no todas las personas discapacitadas son incapaces ${ }^{11}$. De hecho, únicamente se iniciará un procedimiento de incapacitación cuando se estime que puede concurrir alguna de las circunstancias del art. 200 CC, admitiendo incluso el art. 757 de la Ley de Enjuiciamiento Civil (LEC) que pueda instar dicho procedimiento el propio interesado.

Confunde, a mi entender, el voto particular, el sentido de dicha distinción al darle la vuelta y considerar que, puesto que ha de garantizarse la plena igualdad de todas las personas con discapacidad para que participen plena y efectivamente en la sociedad en igualdad de condiciones con las demás, no cabría establecer, según ese argumento, ninguna clase de restricción o límite en el ejercicio de derechos por las personas que, siendo discapacitadas resulten incapacitadas judicialmente, lo cual es negar la evidencia de situaciones en que resulta imposible, por las circunstancias o enfermedades o deficiencias psíquicas, que ciertas personas puedan hallarse en condiciones necesarias para el ejercicio por sí solas de determinados derechos, y, en particular, el ejercicio del derecho de sufragio activo de modo personal, libre y secreto ${ }^{12}$.

La cuestión que subyace en este punto es mucho más general y no se debe entender limitada únicamente al ejercicio del derecho de sufragio activo, sino a todos los derechos fundamentales y a la situación que afecta a las personas afectadas de alguna discapacidad, y es la de discernir si la persona en cuestión goza de la capacidad natural de querer y entender suficiente para el ejercicio de uno u otro derecho.

Desde la perspectiva de la regulación de la Convención de Nueva York, que ampara y se refiere a todas las situaciones de discapacidad en que se pueda encontrar una persona, se trata de garantizar su dignidad y autonomía a todos los efectos, como se desprende de su art. 3, según el cual, entre otros, señala como principios de la misma Convención «el respeto de la dignidad inherente, la autonomía individual, incluida la libertad de tomar las propias decisiones, y la independencia de las personas», «la no discriminación» o «la accesibilidad»; de su art. 5, que consagra la igualdad de todas las personas ante la ley y el derecho a la igual protección legal, así como el derecho a beneficiarse de la ley en igual medida, sin discriminación alguna, estableciendo que los Es-

11 María del Carmen García Garnica señala que no se puede confundir discapacidad con falta o limitación de la capacidad de obrar. Una persona puede padecer (por edad o enfermedad) una discapacidad física, psíquica o sensorial, sin que sea preciso limitar su capacidad de obrar (García Garnica, 2013: 2042).

12 Piénsese, por ejemplo, en una persona aquejada de un grave alzhéimer que ha perdido las facultades cognitivas necesarias y que no puede ni siquiera expresar su voluntad o prestar su consentimiento. 
tados miembros prohibirán toda discriminación por motivos de discapacidad y garantizarán a todas las personas con discapacidad protección legal igual y efectiva contra la discriminación por cualquier motivo»; y, sobre todo, el art. $12^{13}$ de la citada Convención, que consagra el igual reconocimiento como persona ante la ley de las personas con discapacidad.

$\mathrm{Al}$ amparo de esta Convención y de los preceptos citados, se aboga por la sustitución del sistema denominado «médico» de incapacitación, que es el que se dice aún aparece recogido en la legislación civil española (arts. 199 CC, arts. 757 y siguientes de la LEC, o el propio art. 3 LOREG), cuya consecuencia es la declaración judicial de incapacitación de las personas incapaces, con la consiguiente sustitución de la actuación de las mismas en la vida cotidiana por sus tutores o representantes, o la privación del ejercicio de derechos como el de sufragio activo, por un sistema denominado «social», que es el que parece preconizar la Convención de Nueva York, el cual, según se pone de relieve por la doctrina, consistiría en el reconocimiento del ejercicio de la capacidad jurí-

13 El art. 12 de la Convención de Nueva York dispone lo siguiente:

«1. Los Estados miembros reafirman que las personas con discapacidad tienen derecho en todas partes al reconocimiento de su personalidad jurídica.

2. Los Estados miembros reconocerán que las personas con discapacidad tienen capacidad jurídica en igualdad de condiciones con las demás en todos los aspectos de la vida.

3. Los Estados miembros adoptarán las medidas pertinentes para proporcionar acceso a las personas con discapacidad al apoyo que puedan necesitar en el ejercicio de su capacidad jurídica.

4. Los Estados miembros asegurarán que en todas las medidas relativas al ejercicio de la capacidad jurídica se proporcionen salvaguardias adecuadas y efectivas para impedir los abusos de conformidad con el derecho internacional en materia de derechos humanos. Esas salvaguardias asegurarán que las medidas relativas al ejercicio de la capacidad jurídica respeten los derechos, la voluntad y las preferencias de la persona, que no haya conflicto de intereses ni influencia indebida, que sean proporcionales y adaptadas a las circunstancias de la persona, que se apliquen en el plazo más corto posible y que estén sujetas a exámenes periódicos por parte de una autoridad o un órgano judicial competente, independiente e imparcial. Las salvaguardias serán proporcionales al grado en que dichas medidas afecten a los derechos e intereses de las personas. 5. Sin perjuicio de lo dispuesto en el presente artículo, los Estados miembros tomarán todas las medidas que sean pertinentes y efectivas para garantizar el derecho de las personas con discapacidad, en igualdad de condiciones con las demás, a ser propietarias y heredar bienes, controlar sus propios asuntos económicos y tener acceso en igualdad de condiciones a préstamos bancarios, hipotecas y otras modalidades de crédito financiero, y velarán por que las personas con discapacidad no sean privadas de sus bienes de manera arbitraria». 
dica (ex art. 12.3 de la Convención de Nueva York) por el discapacitado, con la asistencia, en su caso, de los sistemas de apoyo que precise, atendiendo a su situación personal, definida fundamentalmente en relación con su entorno y circunstancias concretas, y no tanto desde el punto de vista de sus posibles afecciones médicas ${ }^{14}$.

Así entendido, se podría comprender la postura de la parte recurrente en amparo y del Ministerio Fiscal en su recurso de súplica cuando se pone de relieve la vulneración del art. 23.1 CE por incumplimiento del art. 29 de la Convención de Nueva York y de sus demás preceptos citados en relación con los arts. 10.2 y $14 \mathrm{CE}$, por cuanto no se podría privar de derecho alguno a la persona discapacitada por tal motivo, sino que habría que dotarla de los correspondientes mecanismos de apoyo o asistencia en lugar de privarla del ejercicio del derecho de sufragio, considerando, además, que la discapacidad, como causa de privación del ejercicio de tal derecho, sería discriminatoria.

Sin embargo, y sin perjuicio de la posible reforma de la normativa específica en la materia para adaptarla mejor a la Convención de Nueva York, cabe defender que el sistema regulado por el CC y por la LEC es perfectamente compatible con la Convención de Nueva York, y, que, cuando se hace la distinción entre discapacidad e incapacidad o incapacitación, sí puede entenderse en el sentido de que la incapacidad hace referencia no a una discapacidad en general, sino a una discapacidad consistente en una situación en que la persona carece de la capacidad natural necesaria para poder ejercitar, en este caso, el derecho de sufragio, por no poder formarse una voluntad y tomar una decisión el ciudadano, personal, libre, consciente, autónoma y secreta para votar con las plenas garantías tanto para él, como votante, como para el propio sistema electoral, cuya limpieza y eficacia han de quedar garantizadas en la medida de lo posible.

Así, por tanto, el art. 199 CC, en protección de la persona aquejada de alguna de las deficiencias del art. 200 del mismo cuerpo legal, hace imprescindible la sentencia firme para poder incapacitarla; y, además, el propio procedimiento judicial previsto en la LEC garantiza la flexibilidad y adaptación del caso concreto a las necesidades de la persona discapacitada tanto en cuanto al alcance de la incapacitación como en cuanto al organismo al que se encomien-

14 Dice Roberto M. Jiménez Cano (2010: 70) que en el modelo social las causas que originan la discapacidad se consideran "preponderantemente sociales» y tienen su raíz en una sociedad que, al no tener en cuenta las necesidades de determinadas personas, no presta adecuadamente sus servicios ni asegura sus necesidades; mientras que en el «modelo médico» las causas de la discapacidad no se valoran como sociales, sino individuales, en concreto, médicas o biológicas. 
de la tutela o el mecanismo de guarda o asistencia correspondiente, dado que, por una parte, los arts. 757 y 759 LEC permiten que sea el propio presunto incapaz quien pueda solicitar la declaración de su propia incapacidad y el nombramiento de las personas que hayan de asistir o representarlo y velar por él; quedando así contemplada esa idea y posibilidad de asistencia que parece preconizar la Convención de Nueva York ${ }^{15}$.

Por otra parte, el art. 760 LEC establece que la sentencia determinará la extensión y los límites de la incapacitación, así como el régimen de tutela o guarda a que haya de quedar sometido el incapacitado. De este modo, y siempre que se aplique bajo inspiración de la Convención de Nueva York, lo cual exige, por otra parte, el art. 10.2 CE, podrá crearse, al amparo de la normativa vigente, «un traje a medida» para la persona cuya capacidad judicial quede modificada en virtud de la sentencia, lo que determinará qué puede o no hacer por sí sola o convenientemente asistida y, particularmente, si puede ejercitar el derecho de sufragio activo; una precisión que, asimismo, exige el art. 3 LOREG, de modo que, solo si se hace una valoración en concreto de esta medida y se decide la privación del ejercicio del derecho de sufragio, el discapacitado cuya capacidad se haya modificado judicialmente no podrá votar.

El art. 761 LEC, permite, además, que, sobrevenidas nuevas circunstancias, pueda instarse, incluso por el propio incapacitado, a que se deje sin efecto o modifique el alcance de la incapacitación, lo que sería coherente con el principio de autonomía de la persona que se recoge en el art. 3 de la Convención de Nueva York, lo cual permitiría, igualmente, la recuperación del ejercicio del derecho de sufragio aquí en cuestión. La tutela o la curatela que se establezcan para la representación o asistencia del discapacitado cuya capacidad se haya modificado judicialmente podrá y deberá adaptarse, de este modo, a la situación concreta de la persona, dándose cumplimiento a las exigencias de la Convención de Nueva York ${ }^{16}$. De este modo, la misma persona que hubiera sido privada del ejercicio del derecho de sufragio podría solicitar su recuperación instando el correspondiente proceso para dejar sin efecto o modificar la sentencia en la que se hubiere dispuesto dicha medida.

15 Admite Patricia Cuenca Gómez (2012: 211) que «en algunas situaciones — por ejemplo, en aquellas circunstancias en las que no es posible por ningún medio conocer la voluntad de la persona - la necesidad de apoyo será tan intensa que consistirá en la práctica en una «acción de sustitución»».

16 Dice Montserrat Pereña Vicente (2011: 204) que la Convención no pretende imponer a los Estados que sustituyan sus instituciones por otras, sino que cada Estado respete sus postulados y principios; y que el propio artículo 23.2 de la Convención reconoce y respeta la existencia de la tutela en algunos Estados. 
Lo que parece indiscutible es que, cuando una persona carece de la necesaria capacidad natural de querer y entender para formar su voluntad y prestar su consentimiento, no podrá ejercitar por sí sola sus derechos, ni siquiera con el apoyo o asistencia de persona alguna, cuando se trate de derechos personalísimos que no puede ejercitar más que su titular, como es el caso del derecho de sufragio como manifestación de la voluntad de votar en un sentido concreto, el derecho a otorgar testamento ${ }^{17} \mathrm{o}$ el derecho a contraer matrimonio ${ }^{18}$. Y

17 Sin perjuicio del régimen concreto aplicable en los derechos forales y de las posibilidades que contempla el art. $831 \mathrm{CC}$, el párrafo primero del art. $670 \mathrm{CC}$ dispone que «El testamento es un acto personalísimo: no podrá dejarse su formación, en todo ni en parte, al arbitrio de un tercero, ni hacerse por medio de comisario o mandatario».

Estos derechos a otorgar testamento o contraer matrimonio podrán ser ejercitados por la persona que, hallándose judicialmente incapacitada, no haya sido privada expresamente de tal posible ejercicio, siendo lo esencial que tenga la capacidad natural suficiente de querer y entender; del mismo modo que, una persona que carezca de tal capacidad, aunque formalmente no haya sido judicialmente incapacitada no podrá ejercitar tales derechos. A tales efectos, cabe mencionar el art. 663.2. ${ }^{\circ} \mathrm{CC}$ que dispone que "Están incapacitados para testar: 2. ${ }^{\circ}$ El que habitual o accidentalmente no se hallare en su cabal juicio», y el art. 665 CC, que establece que: «Siempre que el incapacitado por virtud de sentencia que no contenga pronunciamiento acerca de su capacidad para testar pretenda otorgar testamento, el Notario designará dos facultativos que previamente le reconozcan y no lo autorizará sino cuando éstos respondan de su capacidad». Y, en sede de sustituciones, por su parte, el art. 776 $\mathrm{CC}$ dispone que «El ascendiente podrá nombrar sustituto al descendiente mayor de catorce años, que, conforme a derecho, haya sido declarado incapaz por enajenación mental. La sustitución de que habla el párrafo anterior quedará sin efecto por el testamento del incapacitado hecho durante un intervalo lúcido o después de haber recobrado la razón». En cuanto al derecho a contraer matrimonio, el art. 56 CC, redactado por la Ley 4/2017, de 28 de junio, de Modificación de la Ley 15/2015, de 2 de julio, de la Jurisdicción Voluntaria, para dar cobertura plena a la exigencia prevista en los arts. 12.3 y 23.1 de la Convención de Nueva York, establece que «Quienes deseen contraer matrimonio acreditarán previamente en acta o expediente tramitado conforme a la legislación del Registro Civil, que reúnen los requisitos de capacidad o la inexistencia de impedimentos o su dispensa, de acuerdo con lo previsto en este Código.

"El Letrado de la Administración de Justicia, Notario, Encargado del Registro Civil o funcionario que tramite el acta o expediente, cuando sea necesario, podrá recabar de las Administraciones o entidades de iniciativa social de promoción y protección de los derechos de las personas con discapacidad la provisión de apoyos humanos, técnicos y materiales que faciliten la emisión, interpretación y recepción del consentimiento 
cualquiera que sea el modelo, médico o social, que sigamos o las instituciones o mecanismos de asistencia o apoyo que se arbitren, cabe entender que, cuando una persona no puede formar ni expresar su voluntad de manera personal y libre, en modo alguno podrá ejercitar los derechos en los que esa capacidad mínima es imprescindible.

La distinción que hace el TC entre discapacidad e incapacidad es coherente con el principio de la presunción de capacidad de las personas y con el carácter excepcional que debe tener la incapacitación de estas y, en particular, el necesario pronunciamiento en concreto sobre, en su caso, la privación del ejercicio del derecho de sufragio para que esta sea acordada por el tribunal de instancia con las garantías adecuadas.

El propio CC, en la modificación que de este se hizo en virtud de la Ley 41/2003, de 18 de noviembre, de Protección Patrimonial de las Personas con Discapacidad y de Modificación del Código Civil, utiliza en algunos casos el término discapacidad y en otros el de incapacitado, precisamente, para referirse a situaciones distintas, pues, como bien hemos indicado, aunque todos los incapaces se hallen dentro de la categoría de personas con discapacidad, el incapacitado judicialmente se encuentra en una situación especial, que acarrea, por razón de las circunstancias concurrentes en el mismo, una limitación en el ejercicio de sus derechos y en su capacidad de obrar. Y la propia modificación terminológica llevada a cabo por la Ley 15/2.015, de 2 de julio, de la Jurisdicción Voluntaria, no rechaza la diferencia entre discapacidad e incapacitación mencionada, pues cuando sustituye el término de incapacitación por la denominación de "capacidad judicialmente modificada» — en la extensión o términos que correspondan, pero usando un término distinto-, lo hace para referirse a un concepto diferente a la discapacidad en sentido general, o a una situación de discapacidad matizada en la que la intervención judicial se ha hecho precisa para establecer un régimen concreto para la persona incursa en una situación específica.

Así, por ejemplo, el art. $813 \mathrm{CC}$, en materia de intangibilidad de la legítima - y precisamente en protección de los incapacitados judicialmente-, no permite que pueda imponerse sobre la legítima «gravamen, ni condición, ni sustitución de ninguna especie, salvo lo dispuesto en cuanto al usufructo de viudo y lo establecido en el art. 808 respecto de los hijos o descendientes judicialmente incapacitados»; mientras que otros preceptos modificados

del o los contrayentes. Solo en el caso excepcional de que alguno de los contrayentes presentase una condición de salud que, de modo evidente, categórico y sustancial, pueda impedirle prestar el consentimiento matrimonial pese a las medidas de apoyo, se recabará dictamen médico sobre su aptitud para prestar el consentimiento». 
por dicha Ley 41/2003 se refieren al discapacitado en lugar de al incapacitado judicialmente, al abarcar la discapacidad un espectro de situaciones mucho más amplio que el de la incapacitación o incapacidad judicialmente declarada, como el art. 756.7. ${ }^{\text {a }} \mathrm{CC}$, relativo a las causas de indignidad sucesoria ${ }^{19}$; el art. 822 CC, relativo a la donación o legado de un derecho de habitación sobre la vivienda habitual cuyo titular haga a un legitimario persona con discapacidad $^{20}$; o el art. 1.041.2 CC, en materia de colación, que excluye de tal caso «los gastos realizados por los padres y ascendientes para cubrir las necesidades especiales de sus hijos o descendientes con discapacidad».

Como en el caso en cuestión, cuando tratamos la discapacidad en el sentido general que se desprende de lo abordado en la Convención de Nueva York, cabe observar que el legislador español ha adoptado medidas tendentes a evitar discriminaciones ocupándose de establecer garantías y medios que permitan, en aplicación de los principios prevenidos en los arts. $9.2^{21}$ y $49^{22} \mathrm{CE}$, y en la línea de lo que después ha establecido el art. 29 de la Convención de Nueva York, el ejercicio del derecho de sufragio a personas con discapacidades de diverso orden, eliminando los obstáculos que impidan o dificulten el ejerci-

19 En el art. 756.7. a , se afirma que «son incapaces de suceder por causa de indignidad [...] 7. ${ }^{\text {a }}$ Tratándose de la sucesión de una persona con discapacidad, las personas con derecho a la herencia que no le hubieren prestado las atenciones debidas, entendiendo por tales las reguladas en los artículos 142 y 146 del Código Civil».

El art. $822 \mathrm{CC}$, en sus párrafos primero y segundo, dispone lo siguiente: «La donación o legado de un derecho de habitación sobre la vivienda habitual que su titular haga a favor de un legitimario persona con discapacidad, no se computará para el cálculo de las legítimas si en el momento del fallecimiento ambos estuvieren conviviendo en ella. Este derecho de habitación se atribuirá por ministerio de la ley en las mismas condiciones al legitimario discapacitado que lo necesite y estuviera conviviendo con el fallecido, a menos que el testador hubiera dispuesto otra cosa o lo hubiera excluido expresamente, pero su titular no podrá impedir que continúen conviviendo los demás legitimarios mientras lo necesiten».

$21 \mathrm{El}$ art. 9.2 CE establece que «Corresponde a los poderes públicos promover las condiciones para que la libertad y la igualdad del individuo y de los grupos en que se integra sean reales y efectivas; remover los obstáculos que impidan o dificulten su plenitud y facilitar la participación de todos los ciudadanos en la vida política, económica, cultural y social».

$22 \mathrm{El}$ art. $49 \mathrm{CE}$ dispone que «Los poderes públicos realizarán una política de previsión, tratamiento, rehabilitación e integración de los disminuidos físicos, sensoriales y psíquicos, a los que prestarán la atención especializada que requieran y los ampararán especialmente para el disfrute de los derechos que este Título otorga a todos los ciudadanos». 
cio de este derecho, como es el caso, por ejemplo, de las personas en situación de analfabetismo o que carezcan de movilidad en las manos ${ }^{23}$, o el de las personas con discapacidad visual, para los que se ha habilitado la posibilidad de acceder a papeletas electorales escritas con el sistema braille, garantizando no solo el sufragio libre, sino también secreto, de la persona aquejada de falta de visión ${ }^{24}$; así como eliminando, en general, otras barreras que puedan impedir el ejercicio del derecho al voto ${ }^{25}$.

Así se prevé, en este sentido, que las personas que carezcan de movilidad y no puedan desplazarse al colegio electoral ni a la oficina de correos para tramitar su voto a distancia puedan contar con el correspondiente procedimiento habilitado para ello mediante el recurso al notario y al voto mediante poder electoral, para lo cual aquel deberá desplazarse al domicilio del elector y autorizar el correspondiente poder en que se designe un representante para

23 A tal efecto, el art. 87.1 LOREG dispone que «Los electores que no sepan leer o que, por discapacidad, estén impedidos para elegir la papeleta o colocarla dentro del sobre y para entregarla al Presidente de la Mesa, pueden servirse para estas operaciones de una persona de su confianza». Este tipo de voto, que se ha denominado voto asistido y mediante el cual es otra persona distinta a la del votante la que confecciona el voto y lo introduce en la urna, se entiende que se efectúa, necesariamente, conforme a la voluntad del elector. Aquí quiebran los principios de personalidad y secreto del voto, pero siempre en aras al principio de universalidad del sufragio como un principio superior; sin embargo, esta posibilidad del voto asistido no cabe si el elector carece de capacidad para expresar su voluntad al respecto; además, el problema no radica en el caso de estos últimos en la imposibilidad de la confección del voto y de introducirlo en la urna, sino en la ausencia de la formación de una voluntad electoral (Gálvez Muñoz y Rubio Lara, 2007: 102-105).

Véase art. 87.2 LOREG, introducido por la Ley Orgánica 9/2007, de 8 de octubre, que ordena al Gobierno que regule los mecanismos de votación específico para las personas ciegas o con discapacidad visual que les permita ejercer su derecho de sufragio, garantizando el secreto del voto; así como el Real Decreto 1612/2007, de 7 de diciembre, y la Orden Ministerial 3817/2007, de 21 de diciembre, que lo desarrollan. El art. 91.2 LOREG, por ejemplo, dispone que «El Presidente de la Mesa vela porque la entrada al local se conserve siempre libre y accesible para las personas que tienen derecho a entrar en él»; y el art. 1 del Real Decreto 605/1999, de 16 de abril, de Regulación Complementaria de los Procesos Electorales, indica que los locales que se elijan para ubicar las mesas electorales «deben ser accesibles a las personas con limitaciones de movilidad». Véase, también, el Real Decreto 422/2011, de 25 de marzo, por el que se aprueba el Reglamento sobre las Condiciones Básicas para la Participación de las Personas con Discapacidad en la Vida Política y en los Procesos Electorales. 
acudir a la oficina de correos para solicitar la documentación correspondiente y, después, enviar el voto por correo ${ }^{26}$.

A este respecto, cabe hacer, también, una mención al problema de la situación en que se pueden encontrar las personas que carecen de capacidad de obrar o natural suficiente y que no han sido incapacitadas judicialmente, pues, mientras no medie dicha incapacitación, como en el propio caso en cuestión se ha hecho constar, nada impide que el incapaz pueda acudir al colegio electoral y depositar su voto si su incapacidad no afecta a su movilidad, aunque ya se haya indicado que el derecho de sufragio, bien entendido, es mucho más que depositar un voto en una urna. En tanto en cuanto no se haya concluido favorablemente el procedimiento judicial de incapacitación, no parece que los miembros de la mesa electoral puedan comprobar ni analizar si una persona carece de capacidad para ejercer su derecho de voto, máxime cuando, además, la capacidad de obrar de las personas se presume ${ }^{27} \mathrm{y}$, para determinar lo contrario, ha de acreditarse y declararse mediante la correspondiente sentencia judicial firme ${ }^{28}$.

26 El art. 72.c) LOREG dispone que «Los electores que prevean que en la fecha de la votación no se hallarán en la localidad donde les corresponde ejercer su derecho de voto, o que no puedan personarse, pueden emitir su voto por correo, previa solicitud a la Delegación Provincial de la Oficina del Censo Electoral, con los requisitos siguientes: [...] c) En caso de enfermedad o incapacidad que impida la formulación personal de la solicitud, cuya existencia deberá acreditarse por medio de certificación médica oficial y gratuita, aquella podrá ser efectuada en nombre del elector, por otra persona autorizada notarial o consularmente mediante documento que se extenderá individualmente en relación con cada elector sin que en el mismo pueda incluirse a varios electores, ni una misma persona representar a más de un elector. La Junta Electoral comprobará, en cada caso, la concurrencia de las circunstancias a que se refiere este apartado $[\ldots] »$.

Véanse, además, el Real Decreto 557/1993, de 16 de abril, sobre Actuación Notarial en Procedimiento de Emisión del Voto por Correo (BOE de 17 de abril de 1993), que modifica el Anexo IV del Reglamento Notarial; el art. 8 del Real Decreto 605/1999, de 16 de abril, de Regulación Complementaria de los Procesos Electorales; la Instrucción de la Junta Electoral Central, de 26 de abril de 1993, sobre la comprobación por la Junta Electoral competente de la concurrencia de las circunstancias a que se refiere el art. 72.c) LOREG (BOE núm. 101, del 28 de abril de 1993; y la Instrucción de la Junta Electoral Central de 26 de abril de 1993, sobre emisión del certificado médico oficial y gratuito a que se refiere el art. 72.c) de la LOREG (BOE núm. 101, de 28 de abril de 1993).

27 Véanse arts. 29, 32 y 322 CC.

28 Silvia Díaz Alabart (2012: 17) sostiene, sin embargo, que, cuando la persona incluida en el censo electoral no se encuentre, de forma claramente perceptible para los 
No obstante, nos encontramos con muchos casos, en los supuestos mencionados de solicitud de poderes electorales para el voto por correo de personas que no se pueden desplazar, en que, obtenido el certificado médico únicamente relativo a dicho extremo, cuando el notario visita en su domicilio a la persona que va a otorgar el poder electoral a otra, la primera, realmente, carece de la capacidad natural de querer y entender suficiente e, incluso, de la voluntad de votar, y, que no ha sido a iniciativa ni a instancias del posible votante de quien ha partido el requerimiento para otorgar el poder electoral, sino de la persona a la que supuestamente va a designar como apoderado para proceder a tramitar la solicitud del voto por correo.

En dichas circunstancias, el notario, que no tiene por cometido declarar la incapacidad de persona alguna, en el ejercicio de su ministerio y conforme al juicio de capacidad que, sin embargo, tiene que realizar como una actividad y exigencia propia del desempeño de su función, no podrá autorizar el poder electoral si estima que la persona que presuntamente lo ha solicitado carece de la capacidad suficiente para otorgar dicha representación o no ha actuado libre, voluntaria y espontáneamente ${ }^{29}$.

miembros de la mesa, en condiciones de ejercitar su derecho al voto por carecer de la capacidad natural necesaria para ello (por ejemplo, por intoxicación etílica o por otras sustancias), se le debe denegar el ejercicio del derecho de sufragio si los componentes de la mesa así lo estiman, pudiendo pedir que un notario dé fe de esta situación, recabando, si fuera preciso, el auxilio de la autoridad. Sin embargo, considero discutible esta postura, pues, no obstante las facultades que concede al presidente de la mesa el art. 91 LOREG, más parecen estas referidas a evitar todo tipo de desórdenes o de actuaciones violentas y a asegurar la libertad de los electores que a privar del ejercicio del derecho de voto a un ciudadano; una privación que debe siempre entenderse de modo restrictivo.

El notario tiene la obligación, en el ejercicio de su función, de comprobar la capacidad de obrar del otorgante del instrumento público y de cerciorarse de que aquel presta su consentimiento libremente y con la información debida, tal y como se desprende, por ejemplo, de lo dispuesto en el art. 17 bis.2.a) de la Ley del Notariado de 28 de mayo de 1862, añadido por el art. 115.1 de la Ley 24/2001, de 27 de diciembre, según el cual: «Con independencia del soporte electrónico, informático o digital en que se contenga el documento público notarial, el notario deberá dar fe de la identidad de los otorgantes, de que a su juicio tienen capacidad y legitimación, de que el consentimiento ha sido libremente prestado y de que el otorgamiento se adecua a la legalidad y a la voluntad debidamente informada de los otorgantes o intervinientes»; y, en términos semejantes, el art. 145 del Reglamento Notarial, aprobado por Decreto de 2 de junio de 1944, y modificado por Real Decreto 45/2007, de 19 de enero, aplicables, por tanto, a los poderes llamados «electorales", a que se refiere el art. 8 del Anexo IV de dicho Reglamento Notarial, redactado conforme al referido real decreto. 


\section{GARANTÍAS EN EL PROCESO CONCRETO DE DECLARACIÓN DE INCAPACITACIÓN O MODIFICACIÓN JUDICIAL DE LA CAPACIDAD CON PRIVACIÓN DEL EJERCICIO DEL DERECHO DE SUFRAGIO ACTIVO}

Si consideramos, en atención a lo previamente señalado, legal y constitucionalmente posible la restricción o privación del ejercicio del derecho de sufragio activo por causa de la falta de capacidad en concreto de una persona, tal y como prevé el art. 3.1.b) LOREG, la cuestión primordial estriba en garantizar la correcta aplicación de este precepto atendiendo a las circunstancias de cada caso en particular y en el procedimiento judicial en virtud del cual se decide esa privación. Esto es, la sentencia en que se decrete la privación del ejercicio de este derecho debe dictarse atendiendo a la situación particular de la persona afectada, después de haberse realizado un análisis pormenorizado del caso y prestando atención específica a esta cuestión del ejercicio del derecho de voto, como uno de los aspectos particulares del procedimiento de incapacitación, y no como una mera cuestión tangencial en la que, de forma automática se decida dicha privación como consecuencia necesaria e inevitable de la declaración de incapacitación o modificación judicial de la capacidad ${ }^{30}$. De forma que, así como ha de señalarse cuál sea el grado de incapacidad y los actos que el declarado incapaz puede realizar por sí mismo, conforme al art. 760 LEC, del mismo modo, en el caso en el que se le prive del derecho del sufragio activo, esta decisión ha de contar con la motivación suficiente basada en el análisis detallado de la situación concreta del incapaz que permite valorar la proporcionalidad y el acierto de la medida adoptada, así como, en su caso, estimar si la privación del derecho ha sido correcta y adecuada.

En el supuesto objeto de análisis, el Ministerio Fiscal, en su recurso de súplica, en línea con lo argumentado por la parte demandante y recurrente en

Asimismo, en sede de testamentos, el propio CC establece esa misma exigencia del juicio de capacidad que ha de realizar el notario cuando dispone en su art. 696 que «El Notario dará fe de conocer al testador o de haberlo identificado debidamente y, en su defecto, efectuará la declaración prevista en el art. 686. También hará constar que, a su juicio, se halla el testador con la capacidad legal necesaria para otorgar testamento». El Tribunal Europeo de Derechos Humanos ha puesto de relieve, en su Sentencia de 20 de agosto de 2010, en el asunto Alajo Kiss vs. Hungría, que la retirada automática del derecho de voto, en ausencia de evaluación judicial individualizada de la situación de los interesados y bajo el único fundamento de una discapacidad mental que necesite una colocación bajo curatela, no puede ser considerada como una medida de restricción del derecho de voto fundada sobre motivos legítimos (\$44). 
amparo, señala que «no puede descartarse, en el caso, la lesión del art. 23.1 CE por parte de los órganos judiciales», lo cual deduce de lo siguiente:

[...] (i) no parece haberse valorado adecuadamente la manifestación realizada por la interesada en la vista de su voluntad de seguir votando, como así había hecho en una ocasión anterior; (ii) no se practicó prueba alguna que acreditara que el ejercicio del derecho de voto cause un perjuicio» a la demandada «o que tuviera perturbada su capacidad de decisión autónoma»; (iii) el nivel de conocimientos políticos ni la supuesta «influenciabilidad» de la persona, no parecen suficientes para privar del derecho fundamental de voto por razón de discapacidad.

A este respecto, el TC señala, en su FJ 4, que es necesario poner de manifiesto que la valoración de las concretas circunstancias de las que las resoluciones judiciales impugnadas deducen la incapacidad para el ejercicio del derecho de voto no solo no evidencia arbitrariedad, irracionalidad o error patente en el discurso, sino que cumple con el canon de motivación reforzada exigible cuando de la restricción del ejercicio de derechos fundamentales se trata. $Y$ añade que las resoluciones impugnadas toman en consideración los datos que se extraen de pruebas practicadas y ponderan la relevancia de esos datos, así como los que apuntan en la decisión contraria para llegar a una decisión que no puede calificarse de irrazonable.

La magistrada discrepante estima, sin embargo, que el TC ha realizado un juicio sobre la motivación de la sentencia recurrida desde la perspectiva del derecho a la tutela judicial efectiva del art. 24.1 CE, cuya infracción, como dice el mismo auto, no ha sido invocada por el Ministerio Fiscal ni por los demandantes de amparo, y señala que el TC «olvida que lo que se discute en el presente amparo es la vulneración del art. 23.1 CE en relación con el art. $14 \mathrm{CE}[\ldots]$ esto es, un derecho sustantivo y no simplemente procesal [...] y ello habría exigido que se realizara una ponderación, un juicio de proporcionalidad» de la limitación del derecho fundamental como apta para lograr un fin constitucional, «que fuera necesaria, en el sentido de que no existiera una medida menos gravosa para conseguir ese fin», y determinando que «los beneficios de la medida fueran mayores que los perjuicios que ha ocasionado", lo que no se encuentra en el auto ni en las resoluciones judiciales impugnadas, según señala en su voto discrepante; $y$ añade:

[...] prescindiendo de la explícita voluntad de la afectada de seguir ejerciendo su derecho de voto, y sin que quedara acreditada su falta de capacidad para adoptar una decisión autónoma, se le priva del derecho de voto por carecer de un cierto nivel de conocimientos políticos y constitucionales. Y que la falta de ese imprescindible juicio de proporcionalidad que exigía el derecho de sufragio afectado descalifica la decisión judicial adoptada, basada en criterios insuficientes desde la perspectiva del 
art. 23.1 CE, interpretado a la luz de la propia Constitución (arts. 9.2 y 49) y de los arts. 2, 12 y 29 de la Convención de Nueva York.

En el caso en cuestión, la decisión adoptada por el tribunal de instancia, y ratificada después en la apelación y en casación, todo apunta a que, efectivamente, la decisión de la privación del ejercicio del derecho de sufragio activo fue precedida de un análisis en concreto que atendía a las circunstancias de la declarada incapaz, tal y como resulta de los antecedentes recogidos en el auto del TC, máxime cuando los demandantes, en particular, solicitaron que se reconociera a la demandada su capacidad para el ejercicio del derecho de sufragio activo (una solicitud que no debe ser requisito para realizar este análisis en especial, que debe tener lugar, en todo caso, para poder acordar tal privación o restricción); por lo que, además, fue especial objeto de análisis por el tribunal.

En este sentido, en la sentencia de primera instancia se hace constar que procede la privación del derecho de sufragio activo a la demandada al constatarse de manera indubitada en las dos exploraciones efectuadas y por el magistrado las notables deficiencias que presentaba en tal particular faceta electoral no solo por su sustancial desconocimiento de los aspectos básicos y fundamentales del sistema político y del mismo régimen electoral, sino por la constatada influenciabilidad manifiesta de esta, que se constató, en particular, también a efectos de prestación del consentimiento para tratamientos médicos, no siendo desvirtuado el informe pericial médico forense por medio de prueba pericial médica de similar naturaleza.

Se consideró irrelevante para desvirtuar esa falta de capacidad que la demandada afirmase en juicio haber votado en una ocasión y su interés en seguir votando, dadas las deficiencias apreciadas en esta, no superables, a juicio del TC, mediante mecanismos de auxilio o apoyo al estilo de los «asistentes de apoyo» del CC de Cataluña ${ }^{31}$. Como tampoco se consideró suficiente para evitar la privación la manifestación de los padres de la demandada favorable al ejercicio por la misma del derecho de sufragio, al no acreditarse, ni siquiera,

31 El art. 226-1 del libro segundo del CC de Cataluña, relativo a la persona y la familia, aprobado por Ley 25/2010, de 29 de julio, dispone que «1. La persona mayor de edad que lo necesite para cuidar de ella misma o de sus bienes, debido a la disminución no incapacitante de sus facultades físicas o psíquicas, puede solicitar a la autoridad judicial el nombramiento de un asistente, de acuerdo con lo establecido por el presente capítulo, por el procedimiento de jurisdicción voluntaria.

"2. La autoridad judicial debe respetar la voluntad de la persona que debe ser asistida en cuanto al nombramiento o exclusión de alguna persona para ejercer la función de asistencia». 
que «la participación futura en procesos electorales de la demandada suponga un derecho necesario y relevante para fomentar su autonomía personal e inserción social.»

Continúa la sentencia de instancia diciendo lo siguiente:

[...] la limitación apreciada en la demanda a nivel electoral no se basa en la exigencia a la misma de una aptitud cognitiva o intelectiva superior a la de otro posible ciudadano y elector ni en el simple desconocimiento por la demandada de las opciones políticas o en la hipotética irrazonabilidad en la elección de opciones por la misma, sino en la estricta y objetiva constatación de su falta de capacidad a efectos políticos y electorales, apreciadas por la médico forense y por el magistrado de forma indubitada.

Como se pone de relieve en la sentencia de apelación, las SSTS 341/2014 y 421/2013 aclaran que la privación del derecho de sufragio activo es legalmente posible y compatible con la Convención de Nueva York siempre que la decisión se adopte examinando

[...] de forma concreta y particularizada las circunstancias e intereses concurrentes, evitando todo automatismo, para calibrar la necesidad de la medida para proteger los intereses del incapaz y del propio interés general de que la participación electoral se realice de forma libre y con un nivel de conocimiento mínimo respecto del hecho de votar y de la decisión adoptada.

Se trata de poder discernir el sentido del voto y de no ponerlo en riesgo mediante la actuación de terceros o, de constatar que la persona conserva la habilidad necesaria para conocer la realidad política y discernir de forma suficiente a quién otorga el voto.

No puede bastar, dice el TC, con la voluntad de votar, «sino que es preciso que se cuente con un bagaje de conocimientos y capacidades vitales que permitan que el voto sea fruto de una verdadera decisión libre e informada, ajena a hipotéticas influencias sobre una débil capacidad de autodeterminación».

No obstante, parece criticable la argumentación empleada por la sentencia de instancia, ya que, si bien se señala que la demandada carecía de capacidad a efectos políticos y electorales, se dice que esto es así «no solo por su sustancial desconocimiento de aspectos básicos y fundamentales del sistema político y del mismo régimen electoral, sino por la constatada influenciabilidad manifiesta de esta». Estos argumentos resultan bastante desafortunados y contradicen el hecho de que no se le exija una aptitud cognitiva superior a la de otro ciudadano o un conocimiento concreto del sistema electoral, como se señala más adelante. Desde este punto de vista, el desconocimiento de los 
aspectos básicos y fundamentales del sistema político y la influenciabilidad mencionada podrían ser elementos apreciados en muchos de los votantes integrantes del cuerpo electoral si se sometiera a cada uno de ellos a un análisis en concreto, al que, sin embargo, solo se somete a la persona inmersa en un procedimiento de incapacitación y que, por el hecho de realizarse, dado que hay que decidir si se la priva o no del ejercicio del derecho de sufragio activo, debe ser objeto de estudio pormenorizado.

No todos los ciudadanos poseen un conocimiento profundo del sistema electoral, y en todo entorno puede tratarse de convencer a las personas más próximas de la idoneidad de un voto en uno u otro sentido, luego este no es motivo ni causa que permita proceder a la privación o restricción en el ejercicio del derecho de sufragio, sino que es preciso un análisis serio que permita tomar dicha decisión al tribunal que dicte la sentencia de incapacitación, basado en la imposibilidad o dificultad manifiesta para la persona en cuestión de poder tomar una decisión de voto así como su ejercicio personal, libre y secreto.

En el caso de concurrir estas circunstancias que impidan el ejercicio del derecho de sufragio activo, cabe, en los términos establecidos por el art. 3 LOREG, la privación con las garantías pertinentes del ejercicio de este derecho fundamental.

Parece que así ocurrió en el caso en cuestión, dado que, como se puso de relieve en la apelación y en casación, no se actuó, como señala el TS, «de forma rutinaria o con inadvertencia hacia este aspecto concreto», sino que dicha persona «fue objeto de atención específica, provocando que se formularan preguntas concretas de interés sobre el mismos, en las varias sesiones que estuvieron con ella» ${ }^{32}$.

\section{CONCLUSIONES}

De conformidad con lo expuesto a lo largo de este análisis, cabe concluir, por una parte, que la privación del ejercicio del derecho de voto que contempla el art. 3.1.b) LOREG no es contraria al art. 23.1 CE ni a la Convención de Nueva York, ya que, como todo derecho fundamental, el derecho de sufragio

32 Concretamente, como se destaca en la sentencia de apelación, constan datos plenamente relevantes como el nivel de competencia curricular de la demandada del primer ciclo de educación (de seis a ocho años); su desconocimiento casi total del valor del dinero o de conceptos legales básicos; su carencia casi total de conocimientos políticos (ignorancia sobre los partidos políticos o contenido de las elecciones) o su falta de capacidad para adoptar decisiones elementales. 
activo no es un derecho absoluto y puede ser objeto de límites y restricciones en la forma prevista legalmente siempre que se respete su contenido esencial. Asimismo, la privación del ejercicio de este derecho a causa de la falta de capacidad o discernimiento suficiente no constituye, per se, un trato discriminatorio cuando la persona se halle en una situación que no le permita ejercitar su derecho al voto de modo libre, voluntario, personal y secreto siempre que así quede suficientemente acreditado en atención a la situación concreta y particular de la persona afectada por esa privación.

Por tanto, admitida la constitucionalidad de la previsión legal que permite la posibilidad de privación del ejercicio del derecho de sufragio activo, lo esencial es asegurar que esta privación se lleve a cabo de un modo fundado y con las garantías pertinentes, atendiendo siempre a la situación de la persona afectada por esta medida, en un procedimiento judicial en el que se hayan tomado todas las precauciones necesarias y evitando todo automatismo en la adopción de las correspondientes decisiones de privación de derechos y de nombramiento de representantes o del establecimiento de las medidas y sistemas de apoyo adecuados a la persona cuya capacidad se modifique judicialmente.

En este sentido, y sin perjuicio de estas conclusiones, sería aconsejable, de lege ferenda, proceder, por un lado, a una modificación de la redacción del referido art. 3 LOREG para facilitar su aplicación conforme a la CE y a la mencionada Convención de Nueva York, dado que, de una parte, dispone que "carecen del derecho de sufragio", lo cual no parece muy preciso, ya que el derecho de sufragio, como tal, corresponde a todo ciudadano, como titular de derechos y obligaciones con plena capacidad jurídica en la forma determinada por la citada ley orgánica, por lo que sería más apropiado sustituir la redacción de ese inciso, por ejemplo, por la expresión «no podrán ejercitar el derecho de sufragio»; y, de otra parte, al indicar las causas por las que se priva del ejercicio del derecho de sufragio activo, adaptar la terminología empleada en ese precepto a la Convención de Nueva York, abandonando y sustituyendo el uso de palabras como incapacidad e incapacitación, que se utilizan en el mismo art., en la línea de lo que ya se ha hecho, parcialmente, por la mencionada Ley 15/2015, de 2 de julio, de la Jurisdicción Voluntaria, modificada después por la Ley 4/2017, de 28 de junio, que ha optado por la denominación de «capacidad modificada judicialmente»; y, por último, concretando la legislación procesal, en cuanto a esta particular privación del ejercicio del derecho de sufragio, exigiendo siempre de los tribunales una motivación específica y muy detallada de por qué se establece tal privación, en todo caso, impidiendo que se convierta en una «cláusula de estilo» en las sentencias de incapacitación (Díaz Alabart, 2012: 14-15), de modo que esta decisión quede siempre limitada a aquellos casos en que falta la capacidad natural mínima, suficiente y 
concreta para poder participar en el proceso electoral como votante de modo personal, libre y secreto.

\section{Bibliografía}

Cuenca Gómez, P. (2012). Los derechos fundamentales de las personas con discapacidad. Un análisis a la luz de la Convención de la ONU. Cuadernos de la Cátedra de Democracia y Derechos Humanos. Madrid: Universidad de Alcalá.

Díaz Alabart, S. (2012). El derecho al sufragio activo de las personas con discapacidad. La visión civilista. Revista de Derecho Privado, 96, 3-24.

Gálvez Muñoz, L.A. y Rubio Lara, P. A. (2007). El régimen de votación de las personas especialmente vulnerables y sus garantías, en particular la penal. Anales de Derecho, 25, 97-131.

García Garnica, M. C. (2013). Comentario al artículo 199 del Código Civil. En R. Bercovitz Rodríguez-Cano (dir.). Comentarios al Código Civil. Tomo II (arts. 152 a 360) (pp. 2041-2052). Valencia: Tirant lo Blanch.

Jiménez Cano, R. M. (2010). Hacia un marco conceptual adecuado de la normativa española sobre personas con discapacidad. En P. Cuenca Gómez (ed.). Estudios sobre el impacto de la Convención Internacional sobre los Derechos de las Personas con Discapacidad en el Ordenamiento Jurídico Español (pp. 65-102). Madrid: Dykinson.

Pereña Vicente, M. (2011). La Convención de Naciones Unidas y la nueva visión de la capacidad jurídica. En J. Pérez de Vargas (dir.) y M. Pereña Vicente (coord.). La encrucijada de la incapacitación y la discapacidad (pp. 193-205). Las Rozas (Madrid): La Ley. 